\section{Penetration of the subarachnoid space by fetal scalp electrode}

Fetal scalp electrodes of various designs are used widely for continuous intrapartum fetal heart rate monitoring. Minor lacerations of the scalp are common, and $1 \cdot 0-4.5 \%$ of infants may develop scalp ulceration or abscess. ${ }^{12}$ We describe two cases in which there was penetration of the subarachnoid space with leakage of cerebrospinal fluid associated with the use of a scalp electrode of the single helix type.

\section{Case reports}

Case 1-A 20 year old primigravida was admitted in spontaneous labour at 38 weeks of gestation. A fetal scalp electrode was applied at $4 \mathrm{~cm}$ cervical dilatation with the fetal head in the left occipitoanterior position. Spontaneous vaginal delivery of a mature boy weighing $3130 \mathrm{~g}$ occurred four hours later. The baby was in good condition with Apgar scores of 9 and 10 at one and five minutes respectively. Three hours after delivery we noted leakage of clear cerebrospinal fluid from the scalp electrode site over the posterior fontanelle. Conservative treatment with a dry dressing, prophylactic antibiotics, and nursing of the baby in a sitting position resulted in resolution of the leak within 48 hours without any apparent complications.

Case 2-A 20 year old primigravida was admitted in spontaneous labour at 39 weeks. A fetal scalp electrode was applied at $3 \mathrm{~cm}$ cervical dilatation with the fetal head in the right occipitoanterior position. Spontaneous vaginal delivery of a mature girl weighing $3050 \mathrm{~g}$ occurred seven hours later. The baby was in good condition with Apgar scores of 9 and 10 at one and five minutes. Routine examination after birth disclosed leakage of clear fluid from the electrode site over the right parietal bone, $2.5 \mathrm{~cm}$ behind the posterior edge of the anterior fontanelle. As in case 1 there was rapid resolution of the leak (in this case within 24 hours) without any neurological complications. The position of the injury suggested that there had been penetration of both bone and dura resulting in the leak.

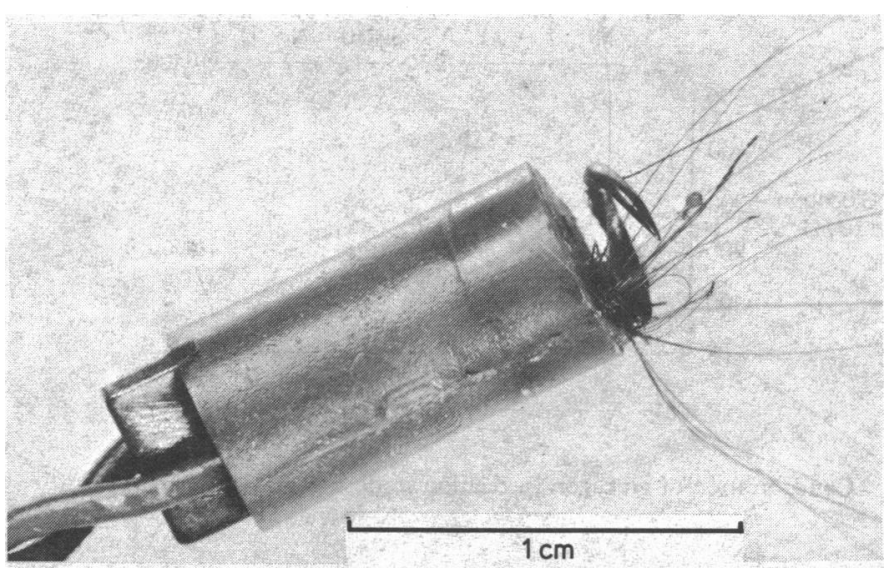

Fetal scalp hair and tissue entrapped between electrode wire and plastic body of device.

\section{Comment}

Penetrating injuries of the skull may lead to infection and meningitis and to intracranial haemorrhage due to vascular injury. There may be a long term risk of epilepsy due to cortical injury and scarring.

In each of these two cases the electrode was applied without difficulty by an experienced midwife. In one the application was unsatisfactory as it was over the posterior fontanelle, but in the other the application was in an ideal position over the parietal bone. Our staff have reported several instances of difficulty in removing these electrodes, and we think that the injuries were sustained during removal rather than application.

There are two important design features of the single helix electrode which contribute to the difficulty of removal. Firstly, the attachment of the helical electrode wire close to the perimeter of the plastic body causes the axis of rotation of the electrode to be indeterminate and variable during both application and removal. Secondly, the narrow angle of insertion of the electrode wire into the plastic body creates a wedge within which fetal scalp hair and tissue may become entrapped (figure). The effect of these design features is such that any traction applied to the electrode during its removal may cause the wire to straighten and thereby increase its potential depth of penetration. Any oscillating rotation which may be used to free the electrode carries the risk of deeper penetration of the tip through the fetal scalp. We think that this is the most likely mechanism for the penetration of the parietal bone in case 2 .

In view of these potentially serious injuries we believe that the use of the single helix scalp electrode should be abandoned in favour of either the double helix or Copeland pattern, whose design features prevent the type of injuries that we describe. ${ }^{3}$

1 Ashkenazi S, Metzker A, Merlob P, Ovadia J, Reisner SH. Scalp changes after fetal monitoring. Arch Dis Child 1985;60:267-9.

Okada DM, Chow AW. Neonatal scalp abscess following intra-partum feta monitoring: prospective comparison of two spiral electrodes. Am $\boldsymbol{\exists}$ Obste Gynecol 1977;127:875-8.

3 Department of Health and Social Security. Helical foetal scalp electrodes. DHSS Safety Information Bulletin 1985; No 21 .

(Accepted 17 fuly 1985)

Department of Obstetrics and Gynaecology, North Manchester General Hospital, Crumpsall, Manchester M8 6RB

D S SHARP, MB, MRCOG, consultant obstetrician

J M COURIEL, MB, MRCP, consultant paediatrician

Correspondence to: Mr Sharp.

\section{Exchange transfusion and quinine concentrations in falciparum malaria}

We were asked to admit a patient with an $80 \%$ falciparum parasitaemia, hyperventilation, and tachycardia. From her description she sounded moribund, so we decided to do an exchange transfusion as soon after admission as possible.

\section{Case history}

In 1985 a white woman aged 38 was referred with falciparum malaria and a parasitaemia of $80 \%$, hyperventilation, and tachycardia after a holiday in Kenya. She had had fever for two weeks, followed by confusion and deafness, before her husband called the doctor. She was drowsy and very weak. Temperature was $39.5^{\circ} \mathrm{C}$, heart rate $127 / \mathrm{min}$, respiratory rate $24 / \mathrm{min}$, weight $82 \mathrm{~kg}$, blood urea concentration $45.3 \mathrm{mmol} / 1(273 \mathrm{mg} / 100 \mathrm{ml})$, bilirubin 31 $\mu \mathrm{mol} / 1(1.8 \mathrm{mg} / 100 \mathrm{ml})$, and platelet count $19 \times 10^{3} / \mathrm{mm}^{3}$.

Ten units of blood were cross matched and a two hour infusion of $500 \mathrm{mg}$ base quinine dihydrochloride $(6.1 \mathrm{mg} / \mathrm{kg})$ in $500 \mathrm{ml}$ isotonic saline started on admission to the intensive care unit at 2130 . A colleague confirmed that the parasitaemia was about $70 \%$, so an exchange transfusion was begun three hours after admission (at 0030) in an attempt to save the patient's life. The blood was transfused into a vein in the right antecubital fossa. Because of difficult peripheral venous access a right subclavian cannula was inserted and 7 units of blood ( 3.51$)$ withdrawn over 130 minutes before the cannula blocked (table). During this time 7 units of stored donor blood were transfused, followed by 2 units of fresh frozen plasma and 6 units of platelets to replenish clotting factors. After the exchange we rechecked the parasitaemia in the blood taken on admission and found it to be $22 \%$. Haemoglobin concentration changed little during the procedure (from 85 to $81 \mathrm{~g} / 1$ ). The 7 units of blood showed a steadily decreasing parasitaemia (from $26 \%$ to $5 \%$ ) and plasma quinine concentration $(18.2$ to $6.5 \mathrm{mmol} / 1 ; 5.9$ to $2.1 \mu \mathrm{g} / \mathrm{ml})$. The patient became more alert during the procedure.

Whole blood exchange ( 7 units) over two hours

\begin{tabular}{lccc}
\hline Time* & $\begin{array}{c}\text { Unit of blood } \\
\text { withdrawn }\end{array}$ & $\begin{array}{c}\text { Parasite count in } \\
\text { unit }(\%)\end{array}$ & $\begin{array}{c}\text { Quinine concentration } \\
\text { in unit (mmol/1) }\end{array}$ \\
\hline 0045 & 1 & 26 & 18.2 \\
0100 & 2 & 19 & 13.9 \\
0125 & 3 & 14 & 12.3 \\
0140 & 4 & 10 & $9 \cdot 2$ \\
0155 & 5 & 8 & 9.5 \\
0230 & 6 & 7 & 7.7 \\
0240 & 7 & 5 & 6.5 \\
\hline
\end{tabular}

* Exchange began at 0030.

Conversion: SI to traditional units-Quinine: $1 \mathrm{mmol} / 1 \approx 0.32 \mu \mathrm{g} / \mathrm{ml}$. 
The patient's temperature fell to $36^{\circ} \mathrm{C}$ in the first 20 hours but then fluctuated up to $38^{\circ} \mathrm{C}$ for five days. Further doses of quinine every 12 hours (maximum $12 \cdot 2 \mathrm{mg} / \mathrm{kg}$ daily) steadily reduced the parasitaemia to zero in six days. The therapeutic concentration of plasma quinine ranged between 10.3 and $25.6 \mathrm{mmol} / \mathrm{l}$ ( 3 and $8 \mu \mathrm{g} / \mathrm{ml}$ ). Six doses were given intravenously (two were only $250 \mathrm{mg}$ ), then 14 by mouth for a total of $9500 \mathrm{mg}$ over nine days, followed by a single dose of $75 \mathrm{mg}$ pyrimethamine and $1500 \mathrm{mg}$ sulfadoxine (three tablets of Fansidar). She became confused on day 7 and her haemoglobin concentration had fallen to $57 \mathrm{~g} / 1$ by day 10 . A 4 unit blood transfusion raised the haemoglobin value to $117 \mathrm{~g} / \mathrm{l}$ and rapidly restored her mental state to normal. Blood films remained negative on days $17,24,38$, and 66 .

\section{Comment}

In other reports all 11 patients treated by exchange transfusion survived, despite initial parasitaemias of between $5 \%$ and $75 \%$ (median $43 \%$ )..$^{1-4}$ By contrast, in a recent study the death rate was $33 \%$ $(15 / 45$ cases) in patients with cerebral inalaria and parasitaemias of $0.04-33 \%$ who did not receive exchange transfusion. ${ }^{5}$

In patients with severe falciparum malaria five to 10 units of blood should be cross matched on admission and exchange transfusion considered, especially if the parasitaemia is over $10 \%$. Intravenous quinine (or quinidine) should be started on admission in a dose of 10 $\mathrm{mg}$ base $/ \mathrm{kg}$ (maximum $500 \mathrm{mg}$ ) given over two hours. Parasite counts and plasma concentrations of quinine at the start and end of each exchange transfusion and infusion of quinine will help determine the dose and timing of quinine. In general, quinine infusions should be given over four hours every 12-24 hours depending on renal and hepatic function.

1 Gyr K, Speck B, Ritz R, Cornu P, Buckner CD, Zerebrale malaria tropica mit schwarzwasserfieber. Schweiz Med Wochenschr 1974;104:1628-30. in cerebral malaria complicated by disseminated intravascular coagulation. Southeast Asian f Trop Med Public Health 1979;10:389-92.

3 Kramer SL, Campbell CC, Moncrieff RE. Fulminant Plasmodium falciparum infection treated with exchange blood transfusion. $\mathcal{A} A M A$ 1983;249:244-5.

4 Chiodini PL, Somerville M, Salam I, Tubbs HR, Wood MJ, Ellis CJ. Exchange 5 White NJ, Warrell DA, Looareesuwan S, Chanthavanich P, Phillips RE, Pongpaew in cerebral malaria. Lancet $1985 ; \mathrm{i}: 776-8$.

(Accepted 17 fuly 1985)

Hospital for Tropical Diseases, London NW1 OPE

ANTHONY HALL, FACP, FRCPED, consultant physician

Intensive Care Unit, University College Hospital, London

ANNE YARDUMIAN, MB, MRCP, clinical lecturer in haematology

ANN MARSH, MRCP, FFARCS, anaesthetic registrar

Correspondence to: Dr Hall.
2 Kurathong S, Srichaikul T, Isarangkura P. Phanichphant S. Exchange transfusion transfusion in severe falciparum malaria. Trans $R$ Soc Trop Med Hyg (in press).

and serologically her lupus activity was quiescent. Normal investigations yielding negative results included stool cultures, parasitology, sigmoidoscopy, biopsy, barium enema, bile and breath test, gastroscopy, and jejunal intubations. Her symptoms continued intermittently until May 1984.

Concentrations obtained from a fasting gut hormone profile were: glucagon $461 \mathrm{IU} / 1$ (normal value $<50 \mathrm{IU} / 1$ ); pancreatic polypeptide $401 \mathrm{IU} / 1<300$ IU/1); vasoactive intestinal peptide $8 \mathrm{IU} / 1(<30 \mathrm{IU} / 1)$; gastrin $10 \mathrm{IU} / 1(<40$ IU/1); and neurotensin $10 \mathrm{IU} / 1(<200 \mathrm{IU} / 1)$. The fasting insulin concentration was $310 \mathrm{mU} / \mathrm{l}(3-20 \mathrm{mU} / \mathrm{l})$ and fasting glucose $4 \cdot 1 \mathrm{mmol} / \mathrm{l}$. Thus the provisional diagnosis of a glucagonoma was made. Clinical examination was normal, and no abdominal mass could be felt. The classical glucogonoma rash was absent. Further investigations yielding negative results included ultrasound examination of liver, gall bladder, and pancreas and computed tomogram of pancreas. Visceral angiography showed a normal pancreas but scattered areas of venous hepatic blush. This raised the possibility of multiple hepatic metastases. Laparotomy showed numerous vascular adhesions over the right side of the liver, making it adhere to the diaphragm. No liver metastases were seen. The peritoneum and pancreas were normal. Biopsy of the liver was normal, and glucagon staining of the liver was negative. There was therefore no evidence of tumour. Venous blushes of the liver on angiography could be accounted for by the vascular adhesions in that area. The diagnosis was therefore unexplained, but severe, hyperglucagonaemia.

The dose of danazol was reduced to $100 \mathrm{mg}$ and subsequently stopped. Glucagon concentrations were monitored regularly, and it appeared that after reducing the dose of danazol there was a consequent reduction in glucagon concentrations (figure), and fasting insulin concentrations returned to within the normal range.

When the drug was withdrawn glucagon concentrations dropped to within the normal range. Clinically, the patient reported that, although diarrhoea was no longer a problem (one to two times each day, normal consistency), she still had vague "butterfly" sensations in her abdomen.

To prove the relation a formal rechallenge with danazol was performed. Glucagon concentration increased again (99 IU/1) three weeks after treatment was restarted. There was no increase in diarrhoea or abdominal discomfort. Danazol treatment was stopped.

\section{Hyperglucagonaemia and treatment with danazol for systemic lupus erythematosus}

A woman with a 19 year history of systemic lupus erythematosus who was treated with danazol to ameliorate pronounced premenstrual flares of her disease is described.

\section{Case report}

A 43 year old woman had been under the care of the Hammersmith Hospital rheumatology unit for 19 years for management of systemic lupus erythematosus. In 1966 she developed polyarthritis and tendinitis, and in 1969 she complained of migraines, diplopia, Raynaud's phenomenon, and symptoms suggesting pleuropericarditis. Her erythrocyte sedimentation rate was $89 \mathrm{~mm}$ in the first hour, and deoxyribonucleic acid binding was $70-90 \%$.

In 1980 it became evident that she suffered lupus "flares" during her premenstrual period. Danazol was given (the first time it had been used for this indication) to try to ameliorate the premenstrual flaring. Initially, a dose of $400 \mathrm{mg}$ daily was given. The clinical effect was good, the drug was well tolerated, and she went into clinical remission.

In January 1984 she complained of loose stools, churning abdominal discomfort, and a $6.75 \mathrm{~kg}$ loss in weight. At this stage her treatment included danazol $200 \mathrm{mg}$ daily (dose had been reduced 24 months previously), prednisolone $10 \mathrm{mg}$ alternate days, and azathioprine $50 \mathrm{mg}$ daily. Clinically

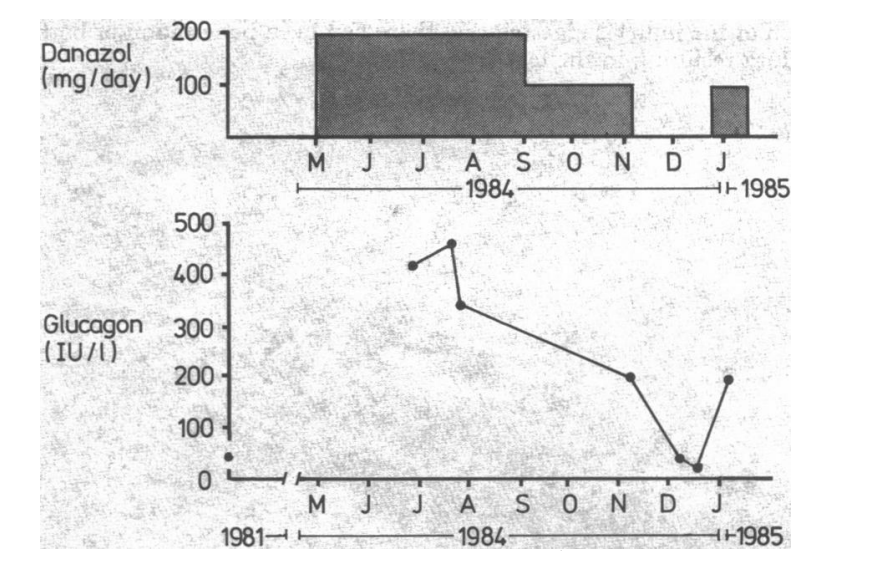

Concentration of glucagon in relation to dose of danazol given.$$
\text { Danazol treatment was stopped. }
$$

$$
\text { Concentration of glucagon in relation to dose of danazol given. }
$$

\section{Comment}

This is the first time that hyperglucagonaemia has been described in relation to treatment with danazol. Danazol is a synthetic steroid, a derivative of ethisterone, and acts as an inhibitor of pituitary gonadotrophin, probably inhibiting both synthesis and release. Morley et al first described its use in two patients with systemic lupus erythematosus (one of whom was the patient mentioned here) who showed premenstrual flaring of the disease. Since then we have gained experience with the drug and found it valuable when used for this indication. Generally it is well tolerated, although in a few patients exacerbation of skin lesions has been troublesome (unpublished observation). No significant oestrogenic or progestational activity has been found. ${ }^{2}$

The importance and clinical implications of this relation between hyperglucagonaemia and danazol are as yet unknown. In this case glucagonaemia was probably related not to systemic lupus erythematosus but to administration of the drug, as evidenced by the return to normal of glucagon concentration when the drug was withdrawn and the fact that the phenomenon was again observed on rechallenge. The clinical syndrome of diarrhoea and abdominal discomfort is extremely rare in association with hyperglucagonaemia and is not associated with the use of danazol.

I thank Drs Graham Hughes, S Morgan, R Bernstein, and M Vickers and 